\title{
PENGARUH EMPLOYEE ENGAGEMENT TERHADAP ORGANIZATIONAL TRUST MELALUI PSYCHOLOGICAL WELL-BEING DAN TRANSFORMATIONAL LEADERSHIP
}

\author{
Yunita Dwi Fridawati \\ Universitas Negeri Surabaya \\ yunita.17080574066@mhs.unesa.ac.id \\ Dwiarko Nugrohoseno \\ Universitas Negeri Surabaya \\ dwiarkonugrohoseno@unesa.ac.id
}

\begin{abstract}
The study investigates how the effect of employee engagement on organizational trust and tests whether psychological well-being and transformational leadership mediate the effect of employee engagement on organizational trust. Companies need organizational trust to produce competent human resources so that be able to achieve company goals. Previous research found that employee engagement affects organizational trust and is mediated by psychological well-being and transformational leadership. Therefore, the research here wants to test the effect of an employee on organizational trust and whether psychological well-being and transformational leadership. The population in this study are 90 employees at PT Kereta Api Indonesia Daop 8 in Surabaya using the snowball sampling method in data collection. The results of the structural model are that employee engagement has a significant impact on organizational trust. Employee engagement has a significant impact on psychological well-being. Employee engagement has a significant impact on transformational leadership; psychological well-being has no significant impact on organizational trust. Transformational leadership has not a significant impact on organizational trust. Employee engagement on organizational trust has not indirect impact by psychological well-being. Employee engagement on organizational trust has not indirect impact by transformational leadership. The managerial implication of this study's result can review the factors that can increase their psychological well-being and transformational leadership on employee engagement. Future research in companies may involve organizational commitment variables, organizational culture variables, and job satisfaction variables because it becomes interesting to involve.
\end{abstract}

Keywords: employee engagement; organizational trust; psychological well-being; transformational leadership.

\section{PENDAHULUAN}

Pada era digitalisasi saat ini, pertumbuhan atau perkembangan suatu organisasi sangat berkaitan dengan teknologi yang semakin maju. Sehingga secara tidak langsung, perusahaan dituntut untuk mampu mempertahankan dan beradaptasi dengan lingkungan yang selalu mengalami perubahan dan kenaikan dalam persaingan yang sangat ketat. Masing-masing dari perusahaan akan memiliki keunggulan yang mampu untuk menarik pelanggan dengan layanan dan produk yang ditawarkan (Porter, 1990).

Sumber daya manusia yang berada di organisasi sangat diperlukan, keberadaannya vital bagi organisasi, untuk dapat merealisasikan dan mencapai visi akan membutuhkan orang-orang yang memiliki kualitas dan berintegritas dalam menyelesaikan tanggung jawabnya. Selain itu, kualitas sumber daya manusia akan menentukan masa depan perusahaan dalam persaingan di era digitalisasi seperti ini (Sutrisno, 2009). Menurut Mathis \& Jackson (2011), manajemen sumber daya manusia ialah seperti rancangan formal yang digunakan oleh organisasi untuk dapat menggunakan bakat yang dimiliki untuk bisa mencapai tujuan dengan sebaik-baiknya secara efektif dan efisien. Berdasarkan hal tersebut, manajemen sumber daya manusia sangat diperlukan agar dapat meningkatkan efektivitasnya di dalam perusahaan atau organisasi (Supomo \& Nurhayati, 2018).

Perusahaan dapat melakukan beberapa hal untuk meningkatkan keunggulan sumber daya manusia, faktor employee engagement adalah salah satu variabelnya (Macey \& Schneider, 2008). Jones \& George (1998) menyatakan bahwa tingkat employee engagement memiliki peran penting dalam 
Yunita Dwi Fridawati \& Dwiarko Nugrohoseno. Pengaruh Employee Engagement terhadap Organizational Trust melalui Psychological Well-Being dan Transformational Leadership

menyukseskan semua tujuan yang telah dibuat perusahaan. Sementara menurut Schaufeli \& Bakker (2004), employee engagement adalah pendorong kesuksesan bisnis, seperti ketekunan karyawan yang terlibat mencapai tujuan organisasi dengan menampilkan proaktif karyawan di tengah situasi yang ada. Li et al. (2021) menegaskan bahwa employee engagement pada umumnya adalah keadaan emosi yang selalu berpikir secara positif, senantiasa bekerja dalam peran yang tinggi dan dicirikan dengan adanya semangat, dedikasi serta penyerapan di dalam pekerjaan. Selain itu, tingkat employee engagement yang berjalan dengan baik secara tidak langsung juga dapat memengaruhi organizational trust di dalam suatu perusahaan (Jena et al., 2018). Organizational trust ialah organisasi yang memiliki kepercayaan terhadap karyawan dan pemimpin yang mampu menciptakan nilai di organisasi untuk disebarkan secara vertikal dan horizontal agar dapat merealisasikan tujuan dari organisasi (Nyhan \& Marlowe, 1997). Menurut Gilbert (2021), organizational trust telah dianggap sebagai variabel yang mampu untuk dapat mengimplementasikan perubahan karena memiliki unsur peningkatan harapan dan motivasi karyawan yang bekerja di suatu perusahaan.

Selain faktor employee engagement, terdapat faktor lain yang juga berpengaruh yaitu, psychological well-being. Ukuran kesenangan atau aspek kebahagiaan dari perasaan seseorang merupakan definisi dari psychological well-being (Russell, 1980). Salah satu variabel yang dapat memengaruhi tingkat perusahaan dalam mencapai organizational trust yaitu psychological well-being (Jena et al., 2018). Hasil penelitian Hashemi et al. (2020) berbeda dari hasil penelitian sebelumnya, yaitu psychological well-being tidak berpengaruh signifikan pada organizational trust.

Organizational trust dapat berkontribusi penuh ke dalam perusahaan, salah satunya ada variabel transformational leadership yang dapat menuntun karyawannya agar bisa mencapai tujuan-tujuan dari perusahaan. Sebuah ciri penting dari transformational leadership adalah mendorong kreativitas karyawan untuk berpikir di luar kotak dan menjadi selalu inovatif. Akhirnya, pertimbangan individual menentukan tingkat pertimbangan pemimpin untuk memenuhi kebutuhan karyawan (Bass, 1997).

Penelitian Rua \& Araujo (2016) membuktikan transformational leadership berpengaruh pada organizational trust. Fenomena adanya transformational leadership banyak dijumpai di suatu perusahaan agar bisa membuat karyawan semakin giat dalam mencapai tujuan perusahaan dan bersaing di dunia industri, salah satu perusahaan itu adalah PT KAI DAOP 8 Wilayah Surabaya. Berdasarkan wawancara awal pada tahun 2019 dengan beberapa karyawan lama menunjukkan adanya perubahan yang terjadi di PT KAI DAOP 8 Wilayah Surabaya sangat terasa, mulai dari kondisi di lingkungan perusahaan yang dulu kurang kondusif, stasiun yang kotor dan banyak penumpang yang tidak memiliki karcis ikut dengan kereta. Namun, dari tahun ke tahun dengan adanya transformational leadership PT KAI DAOP 8 Wilayah Surabaya menunjukkan perbedaan yang jauh semakin bagus di kedepannya. Tujuan penelitian ini adalah untuk mengetahui psychological well-being dan transformational leadership sebagai mediator dan pengaruh employee engagement terhadap organizational trust.

\section{KAJIAN PUSTAKA DAN PENGEMBANGAN HIPOTESIS}

\section{Employee Engagement}

Menurut Schaufeli \& Salanova (2011), adanya employee engagement menyebabkan semangat yang tinggi dalam bekerja. Employee engagement membuat karyawan akan sulit meninggalkan pekerjaannya (Salau et al., 2018). Engagement karyawan yang relatif naik akan menimbulkan perasaan senang pada diri serta cenderung cepat dalam menuntaskan pekerjaan. Employee engagement melihat seberapa jauh mereka dapat bersungguh-sungguh dan menyatukan dirinya ke dalam pekerjaan (Bulinska-Stangrecka \& Iddagoda, 2020). Menurut Schaufeli et al. (2003), employee engagement terdiri dari tiga dimensi pembentuk sebagai berikut. (1) Vigor mencirikan sebagai tingkat energi yang tinggi saat bekerja, kemauan untuk berusaha dan bekerja keras, serta kegigihan terhadap kesulitan di pekerjaan. (2) Dedication yaitu tentang keikutsertaan, keterlibatan, dan rasa antusias dalam suatu pekerjaan. (3) Absorption adalah keadaan saat individu berkonsentrasi secara penuh dan serasa sulit melepaskan diri dari pekerjaannya. 


\section{Organizational Trust}

Organizational trust memiliki kepercayaan pada organisasi, seseorang, dan para pemimpinnya dengan menciptakan sebuah nilai intra organisasi baik secara horizontal maupun vertikal untuk mewujudkan tujuan organisasi (Nyhan \& Marlowe, 1997). Kepercayaan tersebut adalah perasaan percaya diri dan apa adanya dengan keyakinan akan keterlibatan yang berarti (Rua \& Araujo, 2013). Organizational trust harus dapat memahami siapa yang bisa dipercaya dan bagaimana mengontrol orang yang dipercaya tersebut. Selain berdampak positif pada perusahaan, namun ternyata dapat menciptakan sikap negatif seperti karyawan yang memiliki tingkat kepercayaan yang tinggi dapat melakukan tindak kecurangan, memanipulasi, dan penipuan yang justru hal itu dapat membuat penurunan kualitas di perusahaan (Rinendy, 2019). Menurut Yildiz et al. (2017), ukuran organizational trust diperlukan sebagai kondisi untuk kolaborasi organisasi agar maju dan berkembang di kedepannya. Menurut Yu et al. (2018), organizational trust merupakan bentuk kesediaan karyawan untuk membangun hubungan jangka panjang dengan organisasi.

Dimensi organizational trust menurut Shockley-Zalabak et al. (2000) adalah sebagai berikut. (1) Competence yaitu efektivitas pemimpin dan rekan kerja, kemampuan organisasi dalam melakukan suatu hal secara efektif sehingga dapat bersaing dan bertahan dengan yang lain diberbagai macam tempat. (2) Openness meliputi ketepatan dan ketulusan informasi dalam berkomunikasi. (3) Concern menunjukkan perasaan peduli, empati, toleransi, dan keselamatan dalam berhubungan. Menimbulkan keseimbangan kepentingan antara keinginan pribadi dengan orang lain. Keseimbangan antara keinginan seseorang dengan keinginan orang lain merupakan menjadi hal penting yang diperlukan dalam tim dan organisasi. (4) Reliability adalah tindakan yang konsisten dan dapat diandalkan dari rekan kerja, tim, supplier, dan seluruh bagian dari organisasi. (5) Identification merupakan sejauh mana karyawan memegang tujuan, nilai, dan keyakinan bersama dalam suatu organisasi.

\section{Psychological Well-Being}

Menurut Ryff (1989), psychological well-being adalah konsep berkesinambungan dialami individual tentang aktifitas yang terjadi setiap hari dalam pekerjaan yang sedang dilakukannya. Psychological well-being ditandai dengan tingkat kecemasan yang rendah ketika dihadapkan pada situasi di tempat kerja (Nielsen et al., 2009). Psychological well-being juga menekankan proses pertumbuhan individu yang dipengaruhi oleh lingkungan sekitar untuk mencapai sebuah tujuan (Kesawa et al., 2019). Psychological well-being mampu membuat karyawan ketika berada di tempat kerja dapat merealisasikan dirinya dan menghasilkan pekerjaan yang yang lebih baik lagi (Dagenais-Desmarais \& Savoie, 2012).

Ryff (1989) menjelaskan bahwa dimensi-dimensi psychological well-being. (1) Self acceptance, ialah keadaan mengakui segala kejadian diri sendiri dan kehidupan masa dulu. (2) Positive relations with others, yaitu terdapat kualitas interaksi yang baik sesama rekan. (3) Autonomy, adalah kemampuan untuk menetukan tindakan sendiri seperti mandiri dan mengevaluasi diri sendiri. (4) Enviromental mastery, adalah kapasitas untuk mengatur aktivitas lingkungan secara efektif. (5) Purpose in life, adalah percaya dengan setiap kegiatan yang dilaluinya akan menimbulkan kebermaknaan dan bisa mencapai apa yang diharapkan. (6) Personal growth, yaitu mengembangkan potensi diri dan memanfaatkan kapasitas yang dimiliki untuk terus tumbuh dan maju.

\section{Transformational Leadership}

Menurut Azka et al. (2011), transformational leadership merupakan pemimpin yang mengeluarkan segala perhatiannya kepada masalah-masalah yang sedang dihadapi para karyawannya dengan cara memberikan motivasi dan solusi untuk mencapai tujuannya. Transformational leadership dapat memungkinkan mengurangi pengalaman stres dan dampak yang ditimbulkan (Arnold et al., 2007). Transformational leadership dapat bertindak secara optimis dan rahasia, menyatakan visi dengan jelas, dan mampu menjadi pemimpin yang dapat memberikan contoh dan kewenangan terhadap bawahannya untuk mencapai visi perusahaan (Yukl \& Mahsud, 2010). Menurut Pitoyo \& Sawitri (2017), transformational leadership bertujuan menjadikan karyawan agar merasakan adanya kepercayaan, kekaguman, kesetiaan, dan hormat terhadap pimpinan, serta karyawan dapat termotivasi 
Yunita Dwi Fridawati \& Dwiarko Nugrohoseno. Pengaruh Employee Engagement terhadap Organizational Trust melalui Psychological Well-Being dan Transformational Leadership

untuk melakukan pekerjaan dengan cara lebih baik dari yang diharapkan. Memusatkan perhatian pada proses pengaruh timbal balik di antara bawahan sangat diperlukan agar dapat memerkuat proses para pemimpin dalam meningkatkan rasa percaya dan kerjasama di perusahaan (Budiyanti \& Nurman, 2019).

Podsakoff et al. (2006) menjelaskan dimensi dari transformational leadership yang dipakai adalah sebagai berikut. (1) Articulating vision, yaitu memiliki visi, impian yang besar atau ide yang luar biasa yang membutuhkan keberanian pimpinan untuk mampu mewujudkan visi tersebut berjalan sesuai denga apa yang diharapkan. (2) Intellectual stimulations, yaitu pimpinan yang mendorong inovasi dan kreativitas, serta berpikir kritis dan pemecahan masalah. (3) Inspirational communication, merupakan pimpinan yang memiliki komunikasi tepat dan dapat menjadi inspirasi yang sesuai bagi perusahan. (4) Supportive leadership, adalah pimpinan yang mampu untuk melihat kebutuhan dan mempertimbangkan perasaan bawahan ketika bertindak. (5) Personal recognition, adalah pimpinan yang memberikan apresiasi kepada karyawan yang memiliki kinerja tinggi serta yang dapat melakukan pekerjaan sangat baik untuk perusahaannya.

\section{Hubungan antar Variabel}

Pentingnya organizational trust antar pribadi untuk menopang tim dan organisasi terkait dengan berbagai hal proses dan hasil terkait yang mencakup kualitas komunikasi dan pemecahan masalah dalam pekerjaan memiliki kemiripan dengan pentingnya memahami employee engagement (Gillespie \& Mann, 2004). Organizational trust membuat beberapa karyawan menyelesaikan pekerjaan mereka secara efektif dan juga melampaui target tugas karyawan serta bekerja tidak masalah dengan tanpa imbalan. Efek ini lah yang menjadi adanya keterkaitan dan sangat dekat dengan konsep karyawan bekerja ekstra yang merupakan karakteristik dari employee engagement (Schaufeli, 2012). Jena et al. (2018) mengemukakan employee engagement memengaruhi organizational trust secara positif.

H1: Employee engagement berpengaruh signifikan terhadap organizational trust.

Marlatt (2002) mengemukakan bahwa employee engagement berarti dapat membuat mengurangi keputusasaan, kecemasan, dan permusuhan sementara pada karyawan dengan meningkatkan psychological well-being. Robertson \& Cooper (2009), Tripathi (2011), dan Joy \& Sinosh (2017) juga menyelidiki hubungan yang signifikan antara psychological well-being yang merupakan hasil dari sikap karyawan dan merupakan bagian dari pengalaman yang diperoleh berasal dari employee engagement.

H2: Employee engagement berpengaruh signifikan terhadap psychological well-being.

Employee engagement dalam organisasi dipertimbangkan sumber pengembangan, inovasi dan perilaku positif dari pemimpin yaitu dengan adanya transformational leadership yang dapat memungkinkan karyawan untuk berpikir lebih besar dikedepannya (Hayati et al., 2014). Piccolo \& Colquitt (2006) menjelaskan bahwa employee engagement dapat meningkatkan transformational leadership dan berpengaruh signifikan terhadap organisasi. Employee engagement bisa mendorong transformational leadership dalam positif sikap kerja dan meningkatkan kualitas kerja.

H3: Employee engagement berpengaruh signifikan terhadap transformational leadership.

Barak et al. (1998) menyatakan bahwa dimensi organizational trust mencakup proses yang memengaruhi psychological well-being para perempuan di sana terutama prasangka atau pertimbangan yang menghasilkan ketidak adilan di suatu pekerjaan. Mayer et al. (1995), juga menyatakan ada hubungan antara organizational trust dengan psychological well-being di mana pihak organisasi merupakan pihak yang dipercaya yang memiliki kemampuan dan pengaruh serta menunjukkan keinginan tulus untuk membantu meningkatkan organizational trust.

H4: Psychologicall well-being berpengaruh signifikan terhadap organizational trust. 
Suasana kerja yang menarik transformational leadership yang berhubungan dengan karyawan akan ditandai dengan penghargaan dan organizational trust untuk mencapai kesejahteraan yang ada pada diri karyawan tersebut (DeRue et al., 2011). Bass (1985) menyatakan bahwa transformational leadership yang baik mampu secara signifikan meningkatkan organizational trust. Dimensi yang terdapat dalam transformational leadership merupakan bentuk dari leader yang berkompeten dan berintegritas tinggi dalam suatu perusahaan yang akan meningkatkan organizational trust dari karyawan yang berhubungan dengan competen, openness, concern, reliability, dan identification yang ada.

H5: Transformational leadership berpengaruh signifikan terhadap organizational trust.

Employee engagement akan menumbuhkan perhatian dan pikiran di dalam tubuh manusia dalam suasana yang menarik tersebut kemungkinan besar akan menumbuhkan organizational trust. Hal ini telah menambah keyakinan melalui psychologicall well-being sebagai ukuran kesenangan dari perasaan kesejahteraan karyawan diperusahaan (Russell, 1980). Jena et al. (2018) memaparkan bahwa employee engagement yang baik, sungguh-sungguh, loyal akan mencerminkan bentuk organizational trust. Kedua hal ini mampu memiliki hubungan yang baik karena adanya psychologicall well-being yang memediasi employee engagement terhadap organizational trust. Penelitian Saefudin \& Mangundjaya (2018) memerkuat dari pernyataan sebelumnya bahwa employee engagement yang buruk akan menghasilkan organizational trust yang buruk pula. Hal tersebut menyebabkan psychologicall well-being yang merujuk pada stres dan ketidakpuasan terkait pekerjaan serta memengaruhi secara langsung.

H6: Employee engagement berpengaruh signifikan terhadap organizational trust melalui psychologicall well-being.

Transformational leadership memainkan peran penting dan berpengaruh signifikan dalam memediasi employee engagement terhadap organizational trust yang terpancar dari cara tampil dan bekerja yang melebihi ekpektasi yang ada (Jena et al., 2018). Employee engagement yang tinggi di suatu perusahaan maka akan menghasilkan organizational trust yang tinggi pula dan ini dapat dihasilkan melalui transformational leadership yang dapat diterapkan dengan baik di perusahaan (Dvir et al. 2002).

H7: Employee engagement berpengaruh signifikan terhadap organizational trust melalui transformational leadership.

Gambar 1 menunjukkan kerangka konseptual penelitian ini.

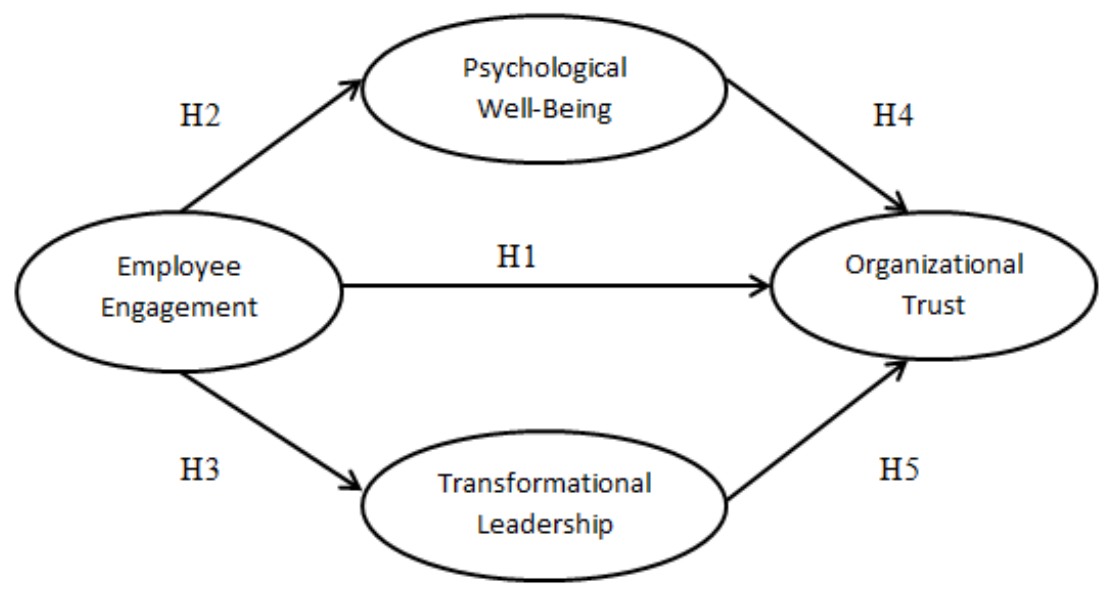

Gambar 1. KERANGKA KONSEPTUAL 
Yunita Dwi Fridawati \& Dwiarko Nugrohoseno. Pengaruh Employee Engagement terhadap Organizational Trust melalui Psychological Well-Being dan Transformational Leadership

\section{METODE PENELITIAN}

Penelitian ini dilakukan secara kuantitatif. Variabel penelitian meliputi employee engagement, organitational trust, psycologival weel-being, dan transformational leadership. Sumber data diperoleh melalui observasi, wawancara, dan survey pada PT KAI DAOP 8 Wilayah Surabaya. Pengambilan data memakai teknik sampling non-probality sampling, dengan jenis snowball sampling. Sebanyak 90 orang karyawan dari PT KAI DAOP 8 wilayah Surabaya yang memenuhi karakteristik sebagai sampel. Olah data menggunakan Partial Least Square dengan aplikasi SmartPLS 3.0.

\section{HASIL DAN PEMBAHASAN}

\section{Karakteristik Responden}

Karakteristik responden berdasarkan usia, jenis kelamin, pendidikan terakhir, masa kerja, dan jabatan. Hasil karakteristik karyawan di PT KAI DAOP 8 wilayah Surabaya berdasarkan usia responden adalah 20-30 tahun adalah 41 orang (45,5\%), 31-40 tahun yaitu 24 orang (26,7\%), 41-50 tahun ialah 15 orang $(16,7)$, dan 51-56 tahun 10 orang $(11,1 \%)$.

Jenis kelamin responden mayoritas laki-laki yaitu 83 orang $(92,2 \%)$ dan sisanya perempuan yaitu 7 orang $(7,8 \%)$. Sebagian besar reponden memiliki pendidikan terakhir SLTA sebanyak 53 orang $(58,9 \%)$, D3 sebanyak 1 orang $(1,1 \%), \mathrm{S} 1$ sebanyak 33 orang $(36,7 \%)$, dan yang terakhir S2 sebanyak 3 Orang (3,3\%). Persentase masa kerja responden adalah 4-10 tahun sebesar 59 orang $(65,5 \%), 11-20$ tahun sebesar 21 orang $(23,3 \%)$, dan 21-30 tahun sebesar 10 orang $(11,1 \%)$.

Karakteristik jabatan dalam penelitian ini adalah jabatan security sejumlah 4 orang $(4,4 \%)$, K3 sejumlah 1 orang $(1,1 \%)$, satker JJ sejumlah 19 orang $(21,1 \%)$, PJL sejumlah 10 orang $(11,1 \%)$, teknisi sejumlah 7 orang $(7,8 \%)$, HRD sejumlah 11 orang $(12,2 \%)$, staf sejumlah 14 orang $(15,6 \%)$, akuntan sejumlah 12 orang $(13,3 \%)$, persinyalan sejumlah 6 orang $(6,7 \%)$, dan humas sejumlah 6 orang $(6,7 \%)$.

\section{Convergent Validity}

Hasil masing-masing dimensi dari setiap variabel akan valid apabila memiliki nilai outerloading > 0,50 (Ghozali \& Latan, 2015). Nilai masing-masing dimensi dapat dilihat pada gambar 2. Semua dimensi dinyatakan valid dikarenakan memiliki nilai outerloading $>0,50$.

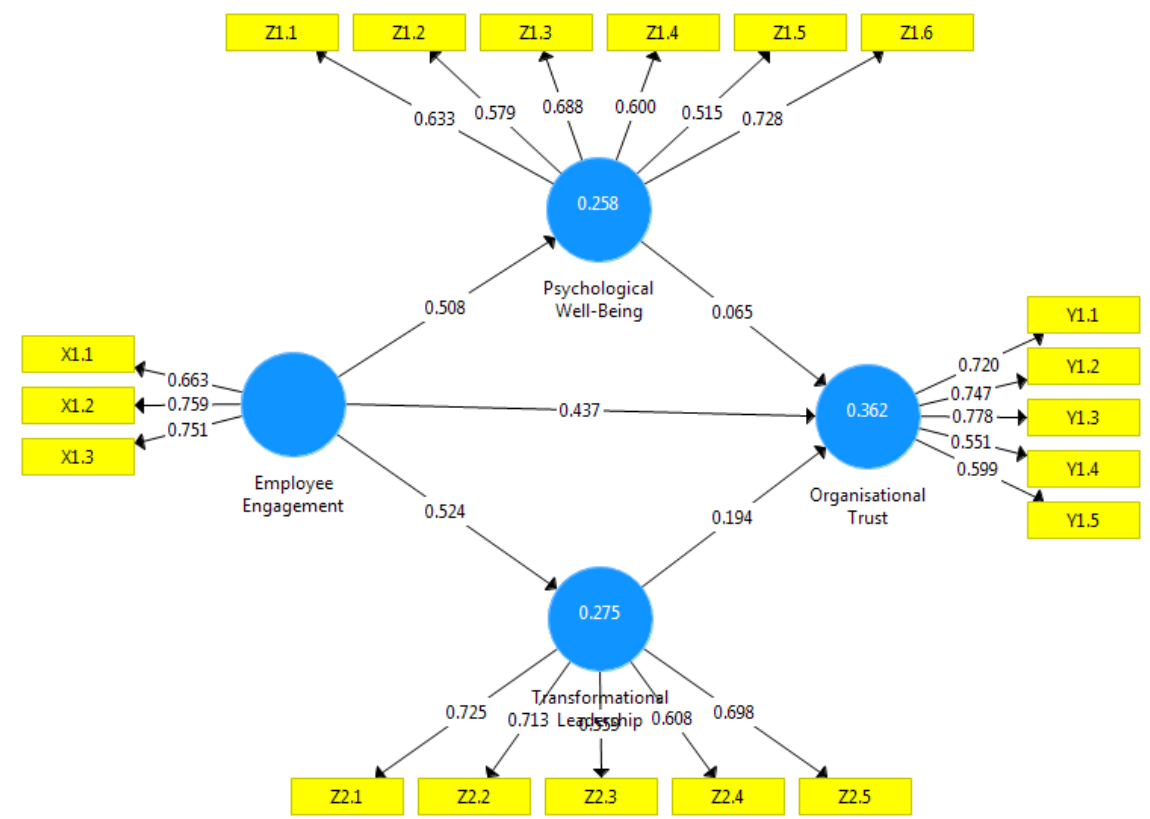

Sumber: Output SmartPLS 3.0 (2021, data diolah)

Gambar 2. MEASUREMENT MODEL 


\section{Composite Reliability dan Cronbach's Alpha}

Nilai Composite reliability ialah $>0,70$ dapat diartikan variabel employee engagement, organizational trust, psychological well-being, dan transformational leadership memiliki reliabilitas yang baik dan tinggi.

Tabel 1.

COMPOSITE RELIABILITY dan CRONBACH'S ALPHA

\begin{tabular}{lcc}
\hline Variabel & Composite Reliability & Cronbach's Alpha \\
\hline Employee engagement & 0,769 & 0,552 \\
Organizational trust & 0,813 & 0,708 \\
Psychologicall well-being & 0,794 & 0,694 \\
Transformational leadership & 0,796 & 0,668 \\
\hline
\end{tabular}

Sumber: Output SmartPLS 3.0 (2021, data diolah)

\section{Analisis R-Square}

Nilai R-square dapat dilihat tabel 2. Nilai R-square menunjukkan variabel employee engagement terhadap organizational trust sebesar 0,362 atau 36,2\%, artinya employee engagement mampu menjelaskan organizational trust sebesar 36,2\% dan sisanya 63,8\% dijelaskan oleh variabel lain. Mengacu di tabel 2, nilai $R$-square sebesar 0,258 artinya pengaruh employee engagement terhadap psychological well-being sebesar $25,8 \%$ dan sisanya adalah $74,2 \%$ dipengaruhi oleh variabel lain. Pengaruh employee engagement terhadap transformational leadership sebesar 0,275. Artinya, 27,5\% variabel transformational leadership dipengaruhi oleh employee engagement sedangkan $72,5 \%$ dipengaruhi oleh variabel lain.

Tabel 2.

$R-S Q U A R E$

\begin{tabular}{lc}
\hline Variabel & $\boldsymbol{R}$-Square \\
\hline Employee engagement & \\
Organizational trust & 0,362 \\
Psychologicall well-being & 0,258 \\
Transformational leadership & 0,275 \\
\hline \multicolumn{2}{l}{ Sumber: Output SmartPLS 3.0 (2021, data diolah) }
\end{tabular}

\section{Uji Kausalitas}

Inner model digunakan untuk mengetahui hubungan antara variabel konstruk dan nilai signifikansi pada tabel path coefficients seperti pada tabel 3 .

Tabel 3.

\section{PATH COEFFICIENTS}

\begin{tabular}{|c|c|c|c|c|}
\hline \multicolumn{2}{|l|}{ Pengaruh antar Variabel } & Original & T Statistik & Keterangan \\
\hline $\begin{array}{l}\text { Employee Engagement } \rightarrow \text { Organi } \\
\text { Trust }\end{array}$ & & 0,437 & 3,138 & $\geq 1,96$ (Signifikan) \\
\hline $\begin{array}{l}\text { Employee Engagement } \rightarrow \text { Psycho } \\
\text { Well-being }\end{array}$ & & 0,508 & 5,381 & $\geq 1,96$ (Signifikan) \\
\hline $\begin{array}{l}\text { Employee } \quad \text { Engagement } \\
\text { Transformational Leadership }\end{array}$ & $\rightarrow$ & 0,524 & 5,786 & $\geq 1,96$ (Signifikan) \\
\hline $\begin{array}{l}\text { Psychological Well-being } \\
\text { Organizational Trust }\end{array}$ & $\rightarrow$ & 0,065 & 0,460 & $\begin{array}{l}\leq 1,96 \text { (Tidak } \\
\text { Signifikan) }\end{array}$ \\
\hline $\begin{array}{l}\text { Transformational Leadership } \\
\text { Organizational Trust }\end{array}$ & $\rightarrow$ & 0,194 & 1,048 & $\begin{array}{l}\leq 1,96 \text { (Tidak } \\
\text { Signifikan) }\end{array}$ \\
\hline
\end{tabular}

Sumber: Output SmartPLS 3.0 (2021, data diolah) 
Yunita Dwi Fridawati \& Dwiarko Nugrohoseno. Pengaruh Employee Engagement terhadap Organizational Trust melalui Psychological Well-Being dan Transformational Leadership

Tabel 3 menjelaskan besarnya nilai estimate coeficient positif sebesar 0,437. Nilai t-statistik pengaruh employee engagement terhadap organizational trust ialah $3,138 \geq 1,96$. Membuktikan hipotesis 1 diterima dan menjelaskan jika variabel employee engagement mempunyai pengaruh terhadap organizational trust. Nilai t-statistik pengaruh employee engagement terhadap psychologicall wellbeing sebanyak $5,381 \geq 1,96$. Artinya terdapat pengaruh signifikan employee engagement terhadap psychologicall well-being, sehingga hipotesis 2 diterima. Nilai estimate coeficient kedua variabel tersebut adalah 0,508 yaitu positif yang berarti apabila employee engagement tinggi maka psychologicall well-being akan menjadi tinggi pula. Makna positif dalam nilai tersebut menggambarkan berbanding lurus dengan nilai t-statistik yang di atas 1,96. Nilai t-statistik pada pengaruh employee engagement terhadap transformational leadership adalah 5,786 $\geq 1,96$, sehingga hipotesis 3 diterima dan terbukti bahwa variabel employee engagement berpengaruh terhadap transformational leadership. Nilai estimate coeficient positif sejumlah 0,524 , membuat semakin tinggi employee engagement maka transformational leadership akan tinggi pula. Nilai t-statistik pengaruh psychological well-being terhadap organizational trust sejumlah $0,460 \leq 1,96$. Jadi tidak ada pengaruh yang signifikan, sehingga hipotesis 4 ditolak. Nilai t-statistik pengaruh transformational leadership terhadap organizational trust ialah 1,048 $\leq 1,96$, mengkibatkan hipotesis 5 ditolak dan variabel transformational leadership tidak mempunyai hubungan terhadap organizational trust.

\section{Indirect Effect}

Berdasarkan hasil pengujian diketahui bahwa nilai koefisien variabel employee engagement terhadap organizational trust melalui psychological well-being berpengaruh langsung dengan nilai koefisien yang besarnya 0,033 dan dengan nilai t-statistik $0,427 \leq 1,96$. Sehingga, psychological well-being tidak dapat menjadi variabel mediasi hubungan antara employee engagement terhadap organizational trust.

Nilai koefisien dari variabel employee engagement terhadap organizational trust melalui transformational leadership sebesar 0,101 dan nilai t-statistik $0,922 \leq 1,96$. Sehingga, variabel transformational leadership tidak dapat menjadi variabel mediasi hubungan antara employee engagement terhadap organizational trust pada perusahaan.

\section{Pengaruh Employee Engagement terhadap Organizational Trust}

Hasil studi membuktikan employee engagement memiliki pengaruh yang positif terhadap organizational trust atau H1 diterima. Artinya, tinggi rendahnya employee engagement memengaruhi organizational trust karyawan. Hasil penelitian ini menunjang dari Gillespie \& Mann (2004), Schaufeli (2012), dan Jena et al. (2018), di mana hasil penelitiannya menyatakan bahwa employee engagement memiliki pengaruh positif terhadap organizational trust. Sehingga menunjukkan employee engagement yang tinggi dapat memengaruhi organizational trust yang tinggi pula.

Fakta yang ditemukan di lapangan dari hasil wawancara terhadap Ibu RN selaku junior manajer SDM PT KAI DAOP 8 wilayah Surabaya, bahwa perusahaan menerapkan beberapa hal agar karyawan merasa konsentrasi dalam melakukan pekerjaannya, sehingga employee engagement dapat tercapai. Seperti karyawan bekerja sesuai dengan jobdesk yang telah diberikan. Selain itu sebagian besar karyawan bekerja secara mandiri dan aktif dalam menyelesaikan pekerjaan yang sudah diberikan. Sehingga dengan adanya kebijakan-kebijakan tersebut, terciptalah karyawan yang bekerja sangat antusias, bangga dan terinspirasi dari pekerjaan yang sedang dilakukan serta membuat tingkat organizational trust di dalam perusahaan semakin tinggi dan menunjukkan hasil yang optimal.

Dimensi reliability mempunyai nilai outerloading terkecil dari dimensi lainnya, sehingga diperlukan kebijakan untuk lebih lagi meningkatkan tindakan yang mampu membuat karyawan dan pemimpin memiliki sikap konsisten dan dapat diandalkan. Selama ini kegiatan yang dilakukan perusahaan untuk meningkatkan organizational trust lebih pada tindakan empati dan peduli seperti selalu mendengarkan masalah karyawan, menjalin hubungan baik dengan cara selalu berkomunikasi dengan karyawan, dan prihatin tentang kesejahteraan karyawan. Maka dari itu, untuk meningkatkan reliability terhadap organisasi, juga dibutuhkan tindakan profesional, seperti bersikap secara konsisten dan dapat diandalkan dari seluruh bagian dari perusahaan baik sesama rekan kerja dan pemimpin. 


\section{Pengaruh Employee Engagement terhadap Psychological Well-being}

Berdasarkan hasil uji data menunjukkan bahwa employee engagement terhadap psychologicall wellbeing memiliki pengaruh secara signifikan positif atau hipotesis kedua diterima terhadap psychological well-being. Hal ini berarti bahwa semakin tinggi employee engagement akan semakin tinggi pula psychological well-being.

Sesuai dengan konsep dari Tripathi (2011), sikap dan pengalaman karyawan yang bagus merupakan bentuk dari employee engagement. Jika hal tersebut diterapkan secara terus-menerus di perusahaan akan memengaruhi psychological well-being pada karyawan yang melakukannya. Karyawan juga merasakan pekerjaan yang dilakukan adalah proses pembelajaran, perubahan, dan pertumbuhan yang berkelanjutan. Karyawan merasa memiliki pengalaman baru yang menantang cara berpikir dalam menyelasaikan pekerjaannya. Penelitian ini mendukung Joy \& Sinosh (2017) dan (Robertson \& Cooper, 2009).

Berdasarkan hasil wawancara terhadap beberapa karyawan, terlihat bahwa adanya employee engagement terhadap perusahaan seperti ketika karyawan mampu dengan baik dalam menjalankan pekerjaannya, merasa antusias dan bangga dengan pekerjaan yang dilakukan. Namun, dari hasil kuesioner yang didapat, terlihat bahwa dimensi vigor mempunyai nilai terkecil dari dimensi-dimensi lainnya, sehingga diperlukan kebijakan untuk lebih lagi meningkatkan semangat yang tinggi saat bekerja. Selama ini kegiatan yang dilakukan perusahaan untuk meningkatkan employee engagement lebih pada kegiatan individual seperti melakukan pekerjaan secara mandiri, dan karyawan harus aktif dalam pekerjaannya. Maka, untuk meningkatkan semangat yang tinggi saat bekerja diperlukan tindakan membantu karyawan dalam pengembangan diri, memberikan saran dan masukan dalam proses menyelesaikan pekerjaannya, serta membuat pekerjaan lebih menyenangkan. Karyawan secara psikologis akan merasa bahagia dan tidak terbebani terhadap tanggung jawab kerja yang akan dilaksanakan. Secara langsung, employee engagement akan meningkatkan psychological well-being semakin tinggi.

Hasil penelitian menunjukkan dimensi purpose in life mempunyai nilai terkecil, di mana bekerja dengan tujuan merupakan salah satu bentuk psychological well-being. Sehingga, diperlukan kegiatan seperti mengespresikan rasa syukur serta menuliskan harapan yang ingin dicapai setiap karyawan di kedepannya. Hal itu akan membuat semangat para karyawan untuk meraih tujuan di pekerjaannya.

\section{Pengaruh Employee Engagement terhadap Transformational Leadership}

Penelitian ini menghasilkan employee engagement mempunyai pengaruh secara positif terhadap transformational leadership, mengartikan hipotesis 3 diterima. Hal ini berarti bahwa semakin tinggi employee engagement akan semakin tinggi pula transformational leadership. Hasil ini sesuai dengan Hayati et al. (2014) dan Piccolo \& Colquitt (2006), employee engagement memengaruhi secara signifikan terhadap transformational leadership. Ketika employee engagement tinggi maka dapat mendorong transformational leadership meningkat dalam perusahaan.

Berdasarkan hasil wawancara terhadap para karyawan, karyawan memiliki dedikasi yang penuh dan tinggi dalam menyelesaikan pekerjaannya, maka mereka secara aktif untuk memberikan aspirasi yang berupa ide, saran atau masukkan yang selainnya yang secara langsung dapat berpengaruh terhadap kebijakan pemimpin dalam menentukan langkah yang tepat dalam rangka meningkatkan kinerja di dalam perusahaan menjadi lebih baik. Hal ini didukung oleh salah satunya dimensi dedication yang dapat menginspirasi dan memiliki nilai yang paling tinggi yang mampu membentuk transformational leadership yang baik. Contohnya, adalah dimensi articulating vision dari transformational leadership yang didorong oleh karyawan PT KAI DAOP 8 Wilayah Surabaya agar mampu memiliki visi dan misi yang baik, ide dan keberanian yang luar biasa untuk mampu mewujudkan visi tersebut agar sesuai dengan yang diharapkan oleh perusahaan. Hal yang sama dinyatakan oleh Ibu RN selaku junior manajer SDM PT KAI DAOP 8 Wilayah Surabaya menyatakan bahwa setiap kebijakan yang diambil oleh pimpinan perusahaan tidak lepas dari peran serta atau keterlibatan karyawan dalam memberikan aspirasinya untuk perbaikan di perusahaan. 
Yunita Dwi Fridawati \& Dwiarko Nugrohoseno. Pengaruh Employee Engagement terhadap Organizational Trust melalui Psychological Well-Being dan Transformational Leadership

\section{Pengaruh Psychological Well-being terhadap Organizational Trust}

Pengujian ini menyatakan bahwa psychological well-being tidak berpengaruh signifikan pada organizational trust atau hipotesis keempat ditolak. Hasil ini mendukung research Wah (1999) dan (Mache et al., 2014). Namun, temuan ini menolak hipotesis awal Barak et al. (1998) dan Mayer et al. (1995) yang menyatakan bahwa organizational trust memengaruhi terhadap psychological well-being.

Berdasarkan wawancara dengan beberapa karyawan, menyatakan psychological well-being tidak berkaitan dengan organizational trust sehingga tidak ada pengaruh yang cukup berarti. Selain itu menurut karyawan organizational trust lebih berkaitan dengan faktor budaya yang diterapkan dalam organisasi, komitmen antar rekan perusahaan, dan kepuasan kinerja karyawan ketika proses bekerja. Hal ini didukung oleh pernyataan Ibu RN selaku junior manajemen SDM PT KAI DAOP 8 wilayah Surabaya yang menyatakan bahwa adanya variabel lain yang bisa lebih berpengaruh untuk memengaruhi organizational trust seperti budaya organisasi, kepuasan kerja, dan komitmen karyawan.

\section{Pengaruh Transformational Leadership terhadap Organizational Trust pada PT KAI DAOP 8 Wilayah Surabaya}

Uji t-statistik antara transformational leadership terhadap organizational trust adalah tidak berpengaruh signifikan sehingga hipotesis kelima ditolak. Penelitian ini bertolak belakang dengan Dickson et al. (2003), dan DeRue et al. (2011) bahwa transformational leadership yang baik akan berhubungan dengan signifikan terhadap organizational trust untuk mencapai kesejahteraan yang ada pada diri karyawan. Penelitian Jena et al., (2018) menyebutkan hasil yang membuktikan bahwa pengaruh transformational leadership terhadap organizational trust adalah tidak berpengaruh signifikan sangat jarang ditemukan karena hal ini merupakan penemuan baru.

Hasil ini diperkuat oleh wawancara dengan beberapa karyawan di PT KAI DAOP 8 wilayah Surabaya, menyatakan bahwa pimpinan telah memberikan motivasi dan inspirasi yang cukup baik terhadap karyawan. Kemudian beberapa karyawan menyatakan, bahwa ada atau tidaknya transformational leadership tidak berpengaruh terhadap organizational trust. Hal ini disebabkan oleh pemahaman dan penanaman pemimpin yang kurang terintepretasikan dengan baik sehingga tidak memengaruhi organizational trust secara signifikan. Ternyata, adanya faktor lain yang lebih memengaruhi organizational trust ialah, komitmen organisasi, kepuasan kerja, dan budaya organisasi. Hal ini didukung oleh pernyataan Ibu RN, selaku junior SDM yang menyatakan bahwa transformatinal leadership yang terjadi di perusahaan masih terjadi salah persepsi di antara karyawan.

\section{Pengaruh Employee Engagement terhadap Organizational Trust melalui Psychological Well- being pada PT KAI DAOP 8 Wilayah Surabaya}

Hasil pengujian total indirect effect untuk melihat mediasi antar variabel diketahui bahwa psychological well-being tidak memediasi pengaruh hubungan employee engagement terhadap organizational trust atau hipotesis 6 ditolak. Temuan ini menolak penelitian Russell (1980), Jena et al. (2018), dan Saefudin \& Mangundjaya (2018) dapat diartikan bahwa variabel employee engagement terhadap organizational trust di PT KAI DAOP 8 Wilayah Surabaya tidak dipengaruhi oleh variabel psychological well-being. Hal ini dikarenakan employee engagement telah berpengaruh secara langsung terhadap organizational trust daripada melalui psychological well-being. Sehingga tanpa melalui mediasi employee engagement sudah memiliki dampak yang positif terhadap organizational trust. Kurangnya penelitian yang menjelaskan tentang hubungan psychological wellbeing sebagai mediasi antara pengaruh employee engagement terhadap organizational trust mengakibatkan penelitian dengan menggunakan variabel ini masih sering diperdebatkan (Jena et al., 2018). Hasil penelitian ini diperkuat oleh wawancara dengan Bapak ZN selaku salah satu staff SDM di PT KAI DAOP 8 wilayah Surabaya yang menyatakan bahwa ada faktor lain yang lebih dibutuhkan untuk meningkakan organizational trust pada diri karyawan terutama tentang budaya di dalam organisasi. 


\section{Pengaruh Employee Engagement terhadap Organizational Trust melalui Transformational Leadership pada PT KAI DAOP 8 Wilayah Surabaya}

Dapat diketahui bahwa nilai total indirect effect pengaruh employee engagement terhadap organizational trust melalui transformational leadership hasilnya adalah tidak signifikan dan hipotesis 7 ditolak. Penelitian ini menolak Dvir et al. (2002) bahwa transformational leadership memediasi pengaruh antara employee engangement terhadap organizational trust. Penemuan ini sangat baru dan hampir tidak ada penelitian secara empiris yang menguji pengaruh employee engagement terhadap organizational trust melalui transformational leadership (Jena et al., 2018). Namun, berdasarkan hasil wawancara faktor lain yang lebih berpengaruh terhadap organizational trust adalah komitmen organisasi, budaya organisasi, dan kepuasan kerja.

\section{KESIMPULAN}

Employee engagement memiliki pengaruh positif terhadap organizational trust, psychologicall wellbeing, dan transformational leadership di PT KAI DAOP 8 wilayah Surabaya. Sementara itu, psychological Well-being dan transformational leadership tidak berpengaruh terhadap organizational trust di PT KAI DAOP 8 wilayah Surabaya. Sedangkan transformational leadership tidak memiliki peran sebagai variabel intervening antara employee engagement terhadap organizational trust dan psychologicall well-being terhadap organizational trust di PT KAI DAOP 8 wilayah Surabaya.

Berdasarkan hasil tersebut adanya implikasi manajerial pada penelitian ini yaitu perusahaan dapat mempertahankan adanya pengembangan kompetensi dan pelatihan agar karyawan mampu belajar untuk bekerja secara konsentrasi, mandiri, dan aktif baik itu di dalam maupun di luar perusahaan, harapannya saran tersebut dapat memertahankan perilaku employee engagement yang dimiliki karyawan di PT KAI DAOP 8 wilayah Surabaya. Perusahaan juga dapat melakukan kegiatan pelatihan kompetensi karyawan agar dapat secara efektif dan berkompeten di bidangnya masingmasing sehingga mampu bersaing diberbagai kondisi. Hal tersebut akan membuat karyawan merasa nyaman dan paham karena sesuai dengan pekerjaan yang mereka lakukan sehingga mampu meningkatkan organizational trust. Selain itu, perusahaan dapat memberikan kegiatan quality time sesama rekan dan pemimpin baik itu moment di dalam atau luar perusahaan. Dengan adanya kegiatan quality time akan memicu karyawan untuk dapat meningkatkan psychological well-being yang dimiliki karyawan. Kemudian, perlu adanya pelatihan kepemimpinan dan evaluasi rutin terhadap para pemimpin dari manajemen puncak seperti apa saja yang sudah terlaksana dan yang seharusnya dilaksanakan di masa depan agar terus mampu bersaing. Kegiatan itu dapat meningkatkan transformational leadership. Sehingga, disarankan untuk penelitian berikutnya agar menambahkan variabel lainnya yang juga memiliki pengaruh terhadap organizational trust yang dimediasi oleh variabel psychological well-being dan transformational leadership yaitu variabel komitmen organisasi, budaya organisasi, dan kepuasan kerja.

\section{DAFTAR PUSTAKA}

Arnold, K. A., Turner, N., Barling, J., Kelloway, E. K., \& McKee, M. C. (2007). Transformational Leadership and Psychological Well-Being: The Mediating Role of Meaningful Work. Journal of Occupational Health Psychology, 12(3), 193-203. https://doi.org/10.1037/10768998.12.3.193

Azka, G., Tahir, M. Q., M, A. K., \& Syed, T. H. (2011). Transformational Leadership, Employee Engagement and Performance: Mediating Effect of Psychological Ownership. African Journal of Business Management, 5(17), 7391-7403. https://doi.org/10.5897/ajbm11.126

Barak, M., Cherin, \& Berkman. (1998). Organizational and Personal Dimensions in Diversity Climate. The Journal of Applied Behavioral, 34(1), 82-104.

Bass, B. M. (1985). Leadership: Good, Better, Best. Organizational Dynamics, 13(3), 26-40. 
Yunita Dwi Fridawati \& Dwiarko Nugrohoseno. Pengaruh Employee Engagement terhadap Organizational Trust melalui Psychological Well-Being dan Transformational Leadership

https://doi.org/10.1016/0090-2616(85)90028-2

Bass, B. M. (1997). Does the Transactional-Transformational Leadership Paradigm Transcend Organizational and National Boundaries? American Psychologist, 52(2), 130-139.

Budiyanti, H., \& Nurman. (2019). Model Kepemimpinan Transformasional Guna Mencapai Kepuasan Kerja Aparatur Sipil Negara ( ASN ). Prosiding Seminar Nasional LP2M UNM, 8, 969-983.

Bulinska-Stangrecka, H., \& Iddagoda, Y. A. (2020). The Relationship Between Inter-Organizational Trust and Employee Engagement and Performance. Academy of Management, 4(1), 8-24. https://depot.ceon.pl/handle/123456789/18195

Dagenais-Desmarais, V., \& Savoie, A. (2012). What is Psychological Well-Being, Really? A Grassroots Approach from the Organizational Sciences. Journal of Happiness Studies, 13(4), 659-684. https://doi.org/10.1007/s10902-011-9285-3

DeRue, S. D., Nahrgang, J. D., Wellman, N., \& Humphrey, S. E. (2011). Trait and Behavioral Theories of Leadership: An Integration and Meta-analytic Test of Their Relative Validity. Personnel Psychology, 64(1), 7-52.

Dickson, M. W., Den Hartog, D. N., \& Mitchelson, J. K. (2003). Research on Leadership in a CrossCultural Context: Making Progress, and Raising New Questions. The Leadership Quarterly, 14(6), 729-768.

Dvir, T., Eden, D., Avolio, B. J., \& Shamir, B. (2002). Impact of Transformational Leadership on Follower Development and Perfomance: A Field Experiment. Academy of Management Journal, 45, 735-744.

Ghozali, I., \& Latan, H. (2015). Partial Least Squares : Konsep, Teknik dan Aplikasi Menggunakan Program Smartpls 3.0 untuk Penelitian Empiris. Semarang: Badan Penerbit UNDIP.

Gilbert, L. L. (2021). The Mediating Impact of Organisational Trust: Overcoming Organisational Hindrance in Managing Organisational Success. European Journal of Research Development and Sustainability (EJRDS), 2(2), 104-115.

Gillespie, N. A., \& Mann, L. (2004). Transformational Leadership and Shared Values: The Building Blocks of Trust. Journal of Managerial Psychology, 19(6), 588-607. https://doi.org/10.1108/02683940410551507

Hashemi, S. E., Qanavati, S., \& Naami, A. (2020). The Effect of Organizational Trust and Workplace Spirituality on Organizational Citizenship Behaviour and Psychological Well-being: Mediating Role of Organization Based Self-Esteem. International Journal Of Psychology (IPA), 14(1), 253-278.

Hayati, D., Charkhabi, M., \& Naami, A. (2014). The Relationship Between Transformational Leadership and Work Engagement in Governmental Hospitals Nurses: a Survey Study. Springer Plus, 3(25), 1-7.

Jena, L. K., Pradhan, S., \& Panigrahy, N. P. (2018). Pursuit of Organisational Trust: Role of Employee Engagement, Psychological Well-Being and Transformational Leadership. Asia Pacific Management Review, 23(3), 227-234. https://doi.org/10.1016/j.apmrv.2017.11.001

Jones, G. R., \& George, J. M. (1998). The Experience and Evolution of Trust: Implications for Cooperation and Teamwork. The Academy of Management Review, 23(3), 531-546. 
Joy, M. M., \& Sinosh. (2017). Employee Engagement -An Empirical Study on Implications For Employee Engagement - An Empirical Study on Implications For Psychological Well-Being. International Journal Of Management (IJM), 7(5), 183-187.

Kesawa, A. H., Fatmawati, I. K., Puspitasari, D. P., Prastyo, B., \& Fazlurrahman, H. (2019). The Effect of Psychological Well-Being and Psychological Empowerment on Job Satisfaction in Intitusion X. International Journal of Advances in Management and Economics, 8(6), 11-15. https://doi.org/10.31270/ijame/v08/i06/2019/2

Li, P., Sun, J. M., Taris, T. W., Xing, L., \& Peeters, M. C. W. (2021). Country Differences in The Relationship Between Leadership and Employee Engagement: A Meta-Analysis. The Leadership Quarterly, 32(1), 1-14. https://doi.org/10.1016/j.leaqua.2020.101458

Macey, W., \& Schneider, B. (2008). The Meaning of Employee Engagement. Industrial and Organizational Psychology: Perspectives on Science and Practice, 1(1), 3-30.

Mache, S., Vitzthum, K., Wanke, E., Groneberg, D. A., Klapp, B. F., \& Danzer, G. (2014). Exploring the Impact of Resilience, Self-Efficacy, Optimism and Organizational Resources on Work Engagement. Work, 47(4), 491-500. https://doi.org/\%0A10.3233/WOR 131617

Marlatt, G. A. (2002). Buddhist Philosophy and The Treatment of Addictive Behavior. Cognitive and Behavioral Practice, 9(1), 44-50. https://doi.org/10.1016/S1077-7229(02)80039-6

Mathis, R. L., \& Jackson, J. H. (2011). Human Resource Management Twelve $e^{\text {th }}$ Edition. United States of America: Thomson South-Western.

Mayer, R. C., Davis, J. H., \& Schoorman, F. D. (1995). An Integrative Model of Organisational Trust. Academy of Management Review, 20(3), 709-734.

Nielsen, K., Yarker, J., Randall, R., \& Munir, F. (2009). The Mediating Effects of Team and SelfEfficacy on the Relationship Between Transformational Leadership, and Job Satisfaction and Psychological Well-Being in Healthcare Professionals: A Cross-Sectional Questionnaire Survey. International Journal of Nursing Studies, 46(9), 1236-1244. https://doi.org/10.1016/j.ijnurstu.2009.03.001

Nyhan, R. C., \& Marlowe, H. A. (1997). Development and Psychometric Properties of The Organizational Trust Inventory. Evaluation Review, 21(5), 614-635. https://doi.org/10.1177/0193841X9702100505

Piccolo, R. F., \& Colquitt, J. A. (2006). Transformational Leadership and Job Behaviors: The Mediating Role of Core Job Characteristics. Academy of Management Journal, 49(2), 327-340. https://doi.org/10.5465/AMJ.2006.20786079

Pitoyo, D. J., \& Sawitri, H. S. R. (2016). Transformational Leadership, Meaning in Work, Leader Member Exchange (LMX), Job Performance dan Work Engagement. Jurnal Bisnis \& Manajemen, 16(2), 15-34. https://doi.org/10.20961/jbm.v16i2.4086

Podsakoff, M., Mackenzie, S. B., \& Moorman, H. (2006). Transformational Leader Behaviors and Their Effects on Followers Trust in Leader, Satisfaction, and Organizational Citizenship Behaviors. Leadership Quarterly, 1(2), 107-142.

Porter, M. E. (1990). The Competitive Advantage of Nations. Harvard Business Review, 68(2), 7393. https://doi.org/10.1177/014920639101700113

Rinendy, J. (2019). The Effects of Organizational Trust To Reduce Employee Fraud Risk in Adventist 
Yunita Dwi Fridawati \& Dwiarko Nugrohoseno. Pengaruh Employee Engagement terhadap Organizational Trust melalui Psychological Well-Being dan Transformational Leadership

University of The Southern Asia Pacific Division. Jurnal Ekonomis, 12(1), 34-46.

Robertson, I. T., \& Cooper, C. L. (2009). Full Engagement: The Integration of Employee Engagement and Psychological Well-Being. Leadership \& Organization Development Journal, 31(4), 324. https://doi.org/10.1108/01437731011043348

Rua, O. M. M. M. D. L., \& Araujo, J. M. C. (2016). Linking Transformational Leadership and Organizational Trust: has Organizational Commitment a Mediating Effect on it? Cuadernos de Gestion, 16(1), 43-62. https://doi.org/10.5295/cdg.140484om

Rua, O. M. M. M. de L., \& Araujo, J. M. C. (2013). The Influence of The Transformational Leadership in the Organizational Trust. Harvard Deusto Business Research, 2(1), 55-66.

Russell, J. A. (1980). A Circumplex Model of Affect. Journal of Personality and Social Psychology, 39(6), 1161-1178. https://doi.org/10.1037/h0077714

Ryff, C. D. (1989). Happiness is Everything, or is it? Explorations on The Meaning of Psychological Well-Being. Journal of Personality and Social Psychology, 57(6), 1069-1081.

Saefudin, A. N., \& Mangundjaya, W. L. . (2018). Peran Modal Psikologis sebagai Mediator untuk Kepercayaan Organisasi dan Keterikatan Karyawan pada Industri Media Televisi. Jurnal Psikologi, 14(2), 102-112.

Salau, O., Oludayo, O., Falola, H., Olokundun, M., Ibidunni, S., \& Atolagbe, T. (2018). Integrated Datasets on Transformational Leadership Attributes and Employee Engagement: The Moderating Role of Job Satisfaction in The Fast Moving Consumer Goods ( FMCG ) Industry. Data in Brief, 4(19), 2329-2335. https://doi.org/10.1016/j.dib.2018.06.032

Schaufeli, W. B. (2012). Work Engagement. What do We Know and Where do We Go? Work Engagement in Everyday Life, Business, and Academia. Romanian Journal of Applied Psychology, 14(1), 3-10.

Schaufeli, W. B., \& Bakker, A. B. (2004). Job Demands, Job Resources, and Their Relationship With Burnout and Engagement: A Multi-Sample Study. Journal of Organizational Behavior, 25(3), 293-315. https://doi.org/10.1002/job.248

Schaufeli, W. B., Bakker, A. B., \& Salanova, M. (2003). The Measurement of Work Engagement With a Short Questionnaire: A Cross-National Study. Educational and Psychological Measurement, 66(4), 701-716. https://doi.org/10.1177/0013164405282471

Schaufeli, W., \& Salanova, M. (2011). Work Engagement: On How to Better Catch a Slippery Concept. European Journal of Work and Organizational Psychology, 20(1), 39-46. https://doi.org/10.1080/1359432X.2010.515981

Shockley-Zalabak, P., Ellis, K., \& Cesaria, R. (2000). Measuring organizational Trust: A Diagnostic Survey and International Indicator. San Francisco: International Association of Business Communicators.

Supomo, R., \& Nurhayati, E. (2018). Manajemen Sumber Daya Manusia. Bandung: Yrama Widya.

Sutrisno, E. (2009). Manajemen Sumber Daya Manusia (Edisi Pert). Jakarta: Kencana.

Tripathi, P. (2011). Employee Well-being: Role of Psychological Capital. Amity Journal of Applied Psychology, 2(1), 18-22. 
Wah, L. (1999). Making knowledge stick. Management Review, 88(5), 24-33.

Yildiz, R. O., Baran, E., \& Ayaz, I. S. (2017). The Effect of Organizational Trust on Work Engangement: An Application on Logistics Personnel. The International New Issues In Social Sciences, 5(5), 139-158.

Yu, M.-C., Mai, Q., Tsai, S., \& Dai, Y. (2018). An Empirical Study on the Organizational Trust, Employee-Organization Relationship and Innovative Behavior from the Integrated Perspective of Social Exchange and Organizational Sustainability. Sustainability, 10(3), 864. https://doi.org/10.3390/su10030864

Yukl, G., \& Mahsud, R. (2010). Why Flexible and Adaptive Leadership is Essential. Consulting Psychology Journal, 62(2), 81-93. https://doi.org/10.1037/a0019835 